\title{
Aplicabilidade da corrente crítica da teoria das restrições no gerenciamento de projetos executivos de engenharia: um estudo de caso em uma refinaria de petróleo
}

\author{
Critical chain of the theory of constraints applied to executive \\ engineering project management: a case study in a petroleum refinery
}

\author{
Éverton Maurer da Silva ${ }^{1}$ \\ Luis Henrique Rodrigues ${ }^{2}$ \\ Daniel Pacheco Lacerda ${ }^{2}$
}

\begin{abstract}
Resumo: Este trabalho tem o objetivo de avaliar a aplicabilidade do método da Corrente Crítica da Teoria das Restrições no gerenciamento de projetos executivos de engenharia em uma refinaria de petróleo. Um problema que necessita de maiores estudos é o ambiente multiprojetos com equipes compartilhadas. Tanto para os modelos clássicos de gestão de projetos, quanto para abordagens alternativas, como a Corrente Crítica, o ambiente multiprojetos apresenta desafios particulares. Nesse sentido, o presente trabalho busca compreender e analisar esse ambiente específico do ponto de vista da Teoria das Restrições. A partir dessa análise se propõe uma sistemática para a implementação da Corrente Crítica nesse ambiente multiprojeto, em particular. O trabalho respeitou os procedimentos recomendados para uma pesquisa qualitativa, especificamente os relativos ao estudo de caso. Os resultados obtidos foram promissores, pois reforçam a necessidade de maiores estudos sobre o gerenciamento de projetos no referido ambiente. Além disso, a proposta de uma sistemática de implementação da Corrente Crítica nesse tipo de ambiente se mostrou apropriada, embora requeira adequações e apresente algumas limitações.
\end{abstract}

Palavras-chave: Gerenciamento de projetos. Teoria das restrições. Corrente crítica.

\begin{abstract}
This paper aims to evaluate the applicability of the Critical Chain of the Theory of Constraints in the management of Executive Engineering projects in a petroleum refinery. The focus is given in the multi-project environment, in which the human resources are shared with the teams being involved in multiple projects simultaneously. This is a challenge both for traditional Project Management approaches, as well as for alternative methods such as the Critical Chain. Therefore, this study analyzes the Critical Chain method in this particular situation and proposes a systematic approach to its implementation in the Executive Engineering Project Management in a petroleum refinery. The paper follows the procedures recommended for qualitative research, especially the ones related to case studies. The results have been promising as they reinforce the need for additional research in the aforementioned environment. In addition, the proposal for an implementation method based on the Critical Chain in this kind of environment has proved to be appropriate requiring however adaptations as it presents certain limitations.
\end{abstract}

Keywords: Project management. Theory of constraints. Critical chain method.

\section{Introdução}

O desenvolvimento de projetos está presente nas organizações e possui distintas dimensões a serem gerenciadas. Os projetos se expressam na organização para o desenvolvimento de produtos, para a implantação de empreendimentos, para mudanças em um processo, entre outros exemplos que poderiam ser citados. A busca por um melhor gerenciamento dos projetos visa reduzir custos, cumprir prazos e entregar a qualidade requerida pelo cliente (RABECHINI JUNIOR; CARVALHO; LAURINDO, 2002; MORAES; LAURINDO, 2003; GIACOMETTI et al., 2007; BARBALHO et al., 2009). Dessa forma, o gerenciamento de projetos tem recebido a atenção de pesquisadores e profissionais, uma vez que possui um papel cada vez mais importante nas organizações. Um indício deste interesse pode

\footnotetext{
${ }^{1}$ Universidade do Vale do Rio dos Sinos - UNISINOS, Av. Castro Alves, 250, Teópolis, CEP 93260-460, Esteio, RS, Brasil, e-mail: evertonmaurer@hotmail.com

${ }^{2}$ Programa de Pós-Graduação em Engenharia de Produção e Sistemas - PPGEPS, Grupo de Pesquisa em Modelagem para Aprendizagem - GMAP, Universidade do Vale do Rio dos Sinos - UNISINOS, Av. Unisinos, 950, Cristo Rei, CEP 93022-000, São Leopoldo, RS, Brasil, e-mails: lhr@unisinos.br; dlacerda@unisinos.br
}

Recebido em 15/11/2010 - Aceito em 24/8/2011

Suporte financeiro: CNPq - Conselho Nacional de Desenvolvimento Científico e Tecnológico (Bolsa Desenvolvimento Tecnológico e Inovação). 
ser observado na Figura 1, a qual apresenta o crescimento exponencial de associados ao PMI Project Management Institute, principal referência e certificador neste tema.

Por um lado, o gerenciamento de projetos individuais apresenta desafios significativos e possui um conjunto de métodos e técnicas consolidados na prática. Por outro lado, a necessidade de redução de custos e melhor utilização dos recursos produtivos exigem ambientes de múltiplos projetos compartilhando recursos. É nessa segunda problemática que esse estudo se inscreve. Para isso, se realiza um estudo no desenvolvimento de projetos executivos de engenharia em uma refinaria de petróleo. Esse é um ambiente multiprojeto no qual os diversos projetos, em desenvolvimento, disputam e compartilham os recursos disponíveis. Assim como outras empresas, essa refinaria precisa ser competitiva e seus projetos precisam cumprir os prazos e os custos previamente estabelecidos.

A relevância do tema gerenciamento de projetos tem por efeito um conjunto de ações tomadas pelas empresas e pela academia. Primeiro, a capacitação em gerenciamento de projetos é uma prática adotada para a adaptação das empresas, por meio de projetos de desenvolvimento de novos produtos ou projetos de melhoria (processos, qualidade etc.), por exemplo. Segundo, a contratação de profissionais especializados em gerenciamento de projetos fomenta tanto o aperfeiçoamento de técnicas existentes, quanto o desenvolvimento de novas. Terceiro, a busca de novas formas de gerenciamento resulta no surgimento de métodos alternativos (Corrente Crítica, Gerenciamento Ágil, Stage-Gate) que procuram mitigar os problemas existentes.

Dentre os diferentes métodos, a Corrente Crítica, que se fundamenta nos princípios da Teoria das Restrições, tem obtido destaque (UMBLE; UMBLE, 2000; WORLEY, 2005). Uma das suas contribuições consiste no reconhecimento de que a duração de um projeto não está unicamente atrelada à rede de tarefas,

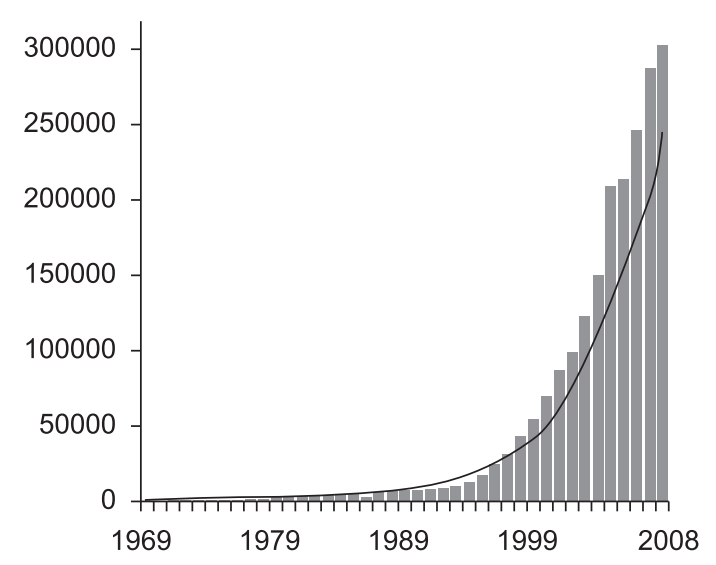

Figura 1. Número de associados ao PMI ao longo do tempo. Fonte: Project Management Institute (2009). mas também na associação com a disponibilidade dos recursos associados (UMBLE; UMBLE, 2000; WORLEY, 2005; MELLO; ZOPPA; GUIMARÃES, 2009; WALKER, 2010). Segundo Newbold (1998), a Corrente Crítica é um dos mais importantes desenvolvimentos na área de gerenciamento de projetos em mais de 30 anos.

A observância dos recursos associados às atividades e às heurísticas de tratamento da Corrente Crítica torna esse método relevante para ambientes multiprojetos. Isso decorre da disputa por recursos entre os projetos em ambientes com essas características. É nesse contexto que esse trabalho se posiciona, uma vez que poucos trabalhos dedicam atenção para Corrente Crítica em um ambiente multiprojetos (COHEN; MADELBAUM; SHTUB, 2004; LEACH, 2005; AGARWAL; BORCHERS, 2009). Dessa forma, esse trabalho procura compreender e analisar os problemas associados ao gerenciamento de projetos em um ambiente multiprojetos. Procurando avançar na discussão, o trabalho se arrisca na proposição de uma sistemática para aplicação dos conceitos da Corrente Crítica nesse ambiente e, em particular, procura avaliar sua aplicabilidade.

Na sequência, são explicitados os principais conceitos que fornecem a sustentação teórica para a análise e proposições que serão realizadas. Em seguida, são evidenciados os procedimentos metodológicos que orientaram a condução da pesquisa. Por fim, a sistemática proposta para a implementação da Corrente Crítica em um ambiente multiprojeto é apresentada.

\section{Referencial teórico}

O referencial teórico aqui apresentado não procura exaurir a discussão dos tópicos relativos ao gerenciamento de projetos, mas sim promover uma revisão suficiente que subsidie a compreensão da Corrente Crítica.

\subsection{A corrente crítica}

A Corrente Crítica foi desenvolvida nos anos 90 e formalmente apresentada em Goldratt (1997). A Corrente Crítica sustenta-se nas premissas e conceitos da Teoria das Restrições e, conforme Silva (2010), apresenta-se como uma alternativa à utilização do Caminho Crítico. Rand (2000) cita que o desenvolvimento da Corrente Crítica pode ser justificado pela existência de problemas crônicos nos métodos e abordagens existentes.

Conforme Goldratt (1997), as incertezas inerentes aos projetos são a principal fonte de problemas no gerenciamento de projetos. As incertezas se originam das dificuldades e obstáculos de difícil previsão no início do projeto que, desconhecidas e imensuráveis em tal momento, passam a ser um problema para o planejamento do projeto, especificamente nas 
estimativas de duração de atividades (HERROELEN; LEUS; DEMEULEMEESTER, 2002; RAZ; BARNES; DVIR, 2004). Para compensar as incertezas, as estimativas dos tempos das atividades são inflacionadas, adicionando segurança.

Goldratt (1997) explica que, estatisticamente, a data de maior probabilidade de finalizar uma atividade apresenta cerca de $50 \%$ de confiança. Isso significa que, em $50 \%$ dos casos, a atividade levará menos tempo e, em outros $50 \%$ dos casos, levará mais tempo que a data de maior probabilidade. Dessa forma, a data que apresenta a maior probabilidade de acerto, também é a data que estará errada em $50 \%$ das vezes, algo que não seria viável, sendo assim pouco utilizada (RAZ; BARNES; DVIR, 2004). Assim, Goldratt (1997) supõe que, em geral, as estimativas possuem uma probabilidade de confiança de 80 a $90 \%$.

A Figura 2 ilustra a situação em que, para se completar uma determinada atividade com $50 \%$ de confiabilidade, seriam necessárias cinco unidades de tempo. Porém, para uma estimativa confortável, com 90\% de confiabilidade, o tempo necessário dobrará, sendo necessárias dez unidades de tempo (LEACH, 1999; HERROELEN; LEUS; DEMEULEMEESTER, 2002). Portanto, nas estimativas das atividades, inserem-se margens de segurança.

Goldratt (1997) apresenta três mecanismos que influenciam o aumento das estimativas de duração das atividades e, por consequência, do projeto. Primeiro, as estimativas de duração são baseadas na experiência pessimista. Segundo, quanto maior o número de níveis gerenciais, maior a duração total da estimativa da atividade, pois os diferentes níveis agregam segurança (UMBLE; UMBLE, 2000). Terceiro, as pessoas estimam as durações protegendo-se de cortes (LEACH, 1999; UMBLE; UMBLE, 2000). Nesse sentido, cabe a reflexão sobre as possíveis causas para o não cumprimento dos prazos apesar das seguranças inseridas nas durações das atividades e dos projetos (LEACH, 1999).

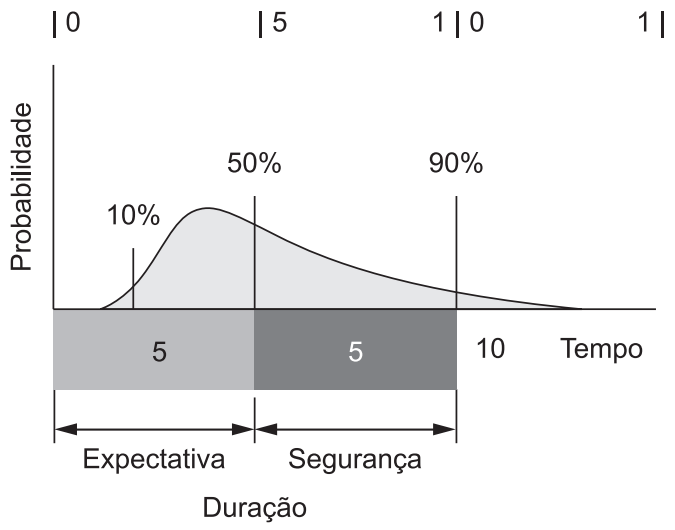

Figura 2. O impacto da confiabilidade nas estimativas de tempo. Fonte: Adaptado de Zultner (2003).
Um fator que pode implicar a falta de cumprimento com os prazos estabelecidos para o projeto é o acúmulo de atrasos e o desperdício das antecipações (COHEN; MADELBAUM; SHTUB, 2004). Por um lado, um atraso em uma atividade implica atraso no início da atividade seguinte. Por outro lado, no caso de concluir uma atividade antecipadamente ao planejado, a antecipação não necessariamente é transferida para outras atividades do projeto (HERROELEN; LEUS; DEMEULEMEESTER, 2002). Conforme explica Goldratt (1997), um atraso numa atividade é repassado por completo para a etapa seguinte, enquanto um avanço feito numa atividade é, geralmente, desperdiçado. Goldratt (1997) argumenta que as estimativas não protegem o projeto como um todo e são desperdiçadas na conexão entre as atividades. Para isso, Goldratt (1997) apresenta três fenômenos que interferem na execução das atividades, quando estas possuem seguranças em suas estimativas de duração.

O primeiro fenômeno é chamado de "síndrome do estudante", o qual consiste em esperar até o último momento para iniciar uma atividade (GOLDRATT, 1997; HERROELEN; LEUS; DEMEULEMEESTER, 2002; BUDD; CERVENY, 2010). Steyn (2000) diz que, ao inserir segurança nas atividades, o pessimismo que prevaleceu na etapa de planejamento é substituído pelo otimismo após o início do projeto. De fato, somente é possível saber que existe um problema em uma atividade ao se iniciar a sua execução. Portanto, iniciando o mais tarde possível, haverá o desperdício da segurança inicialmente estabelecida, exatamente no momento em que problemas poderão surgir, o que levará ao atraso do projeto (WORLEY, 2005; YANG, 2007).

O segundo fenômeno consiste na multitarefa nociva (GOLDRATT, 1997; YANG, 2007). Trata-se de uma consequência gerada pelo ambiente em que diversos projetos são desenvolvidos paralelamente e que, por vezes, tem sua prioridade alterada recorrentemente. A mudança de prioridade do projeto pode ocorrer por diferentes razões e implica a realocação dos recursos nas atividades. Por consequência, o andamento das atividades é cobrado, simultaneamente, do responsável pela sua execução. Na tentativa de atender às demandas, o responsável por executar a atividade alterna entre as atividades antes de concluí-las. Isso gera pequenos progressos em cada uma das atividades e, possivelmente, implica atrasos no projeto pela interdependência das atividades.

Além disso, certo tempo é necessário entre parar uma tarefa e iniciar outra. Por consequência, o somatório destes tempos implica aumento do lead time de cada atividade (GOLDRATT, 1997; WORLEY, 2005). Leach (1999) e Zultner (2003) afirmam haver um tempo de preparação necessário para alternar a atenção entre as atividades, especialmente quando se trata de diferentes atividades em diferentes 
projetos. Um fato que colabora para que a multitarefa seja utilizada é a percepção de que seus efeitos no cronograma do projeto são pequenos. Outro fato é o falso aumento de produtividade na utilização de recursos, visto que com a utilização da multitarefa os recursos estarão trabalhando $100 \%$ do tempo (HERROELEN; LEUS; DEMEULEMEESTER, 2002; ZULTNER, 2003).

O terceiro fenômeno é chamado de Lei de Parkinson (GOLDRATT, 1997). A Lei de Parkinson consiste no princípio de que as atividades tendem a se expandir e ocupar o tempo disponível (RAZ; BARNES; DVIR, 2004; WORLEY, 2005). Steyn (2000) e Budd e Cerveny (2010) afirmam que há pouco incentivo para que se antecipe a conclusão de uma atividade. Por consequência, independente da necessidade, o tempo disponibilizado para a atividade é sempre utilizado. Newbold (1998) afirma que esta é uma fonte da baixa produtividade em projetos e alerta para a dificuldade de observar esse fenômeno. O Quadro 1 sintetiza os mecanismos de acúmulo e desperdício de segurança.

A seguir serão expostas algumas abordagens para a implementação da Corrente Crítica para a gestão de projetos. Inicialmente, se apresenta a abordagem para a gestão em um único projeto. Na sequência, é detalhada a abordagem para implementação em um ambiente multiprojetos.

\subsection{Abordagens para implementação da corrente crítica na gestão de projetos}

Goldratt (1997) propõe como primeiro passo a definição da restrição do sistema, ou seja, a Corrente Crítica, uma vez que esta determina a duração do projeto. Como segundo passo, ao decidir como explorar a restrição, Goldratt (1997) propõe que o tempo do Caminho Crítico não seja desperdiçado com os mecanismos citados anteriormente. Assim, Goldratt (1997) propõe que as atividades tenham início na data mais tarde possível, tenham sua duração estimada com o tempo de maior probabilidade e que

Quadro 1. Mecanismos de acúmulo e de desperdício de segurança.

\begin{tabular}{|c|c|}
\hline $\begin{array}{c}\text { Mecanismos de } \\
\text { acúmulo de segurança }\end{array}$ & $\begin{array}{c}\text { Mecanismos de } \\
\text { desperdício de segurança }\end{array}$ \\
\hline $\begin{array}{c}\text { Estimativas com grande } \\
\text { segurança embutida }\end{array}$ & $\begin{array}{c}\text { Atrasos se acumulam e } \\
\text { avanços são desperdiçados }\end{array}$ \\
\hline $\begin{array}{c}\text { Estimativas baseadas em } \\
\text { experiências pessimistas }\end{array}$ & $\begin{array}{c}\text { Síndrome do } \\
\text { estudante }\end{array}$ \\
\hline $\begin{array}{c}\text { Cada nível hierárquico } \\
\text { adiciona sua margem de } \\
\text { segurança }\end{array}$ & $\begin{array}{c}\text { Lei de } \\
\text { Parkinson }\end{array}$ \\
\hline $\begin{array}{c}\text { As estimativas fornecidas } \\
\text { são protegidas de } \\
\text { possíveis cortes }\end{array}$ & Multitarefa \\
nociva
\end{tabular}

Fonte: Elaborado pelos autores. as proteções quanto às incertezas não sejam inseridas para proteger as atividades individualmente. Ao admitir que o projeto (não as atividades) necessite de proteção quanto às incertezas, Goldratt (1997) informa que a proteção (pulmão) deve ser alocada no final da Corrente Crítica, sendo que sua duração (do pulmão) deverá ser a metade da duração da Corrente Crítica. As flutuações ocorridas nos tempos das atividades se compensam e o excedente é absorvido por um tempo de proteção único. Esta proteção é chamada de pulmão de projeto. Conforme Newbold (1998), a incerteza deve ser minimizada, expressa, jamais ignorada e deve ser parte do planejamento, o que corrobora para com a prática proposta.

Leach (2005) afirma que o método proposto permite proteger a Corrente Crítica com o mesmo grau de confiabilidade, utilizando um menor tempo de contingência. Steyn (2000) explica que iniciar o projeto na data mais tarde tende a minimizar a possibilidade de retrabalho devido a mudanças no escopo, além de melhorar o fluxo de caixa do projeto.

Segundo Goldratt (1997), é necessário também proteger a restrição (corrente crítica) das perdas ocorridas em outros lugares: os caminhos não críticos. A proposta é replicar aos demais caminhos a heurística adotada para a Corrente Crítica. Isso significa reduzir a estimativa de tempo das atividades pela metade e alocar, ao final de cada caminho não crítico, um pulmão de tempo com a metade do somatório das durações da sequência de atividades (YANG, 2007). Neste caso, o pulmão de tempo é denominado pulmão de convergência, ou de alimentação. O pulmão de convergência tem como papel proteger a Corrente Crítica de possíveis atrasos que venham a ocorrer em uma corrente não crítica.

Goldratt (1997) argumenta que, algumas vezes, uma atividade não é iniciada pela falta do recurso apropriado. Para mitigar esse efeito, utiliza-se o conceito de pulmão de recurso. O pulmão de recurso tem o objetivo de garantir a disponibilidade do recurso necessário no início de sua atividade (IOANNOU; PAPADOYIANNIS, 2004). Isso pode ser um simples aviso de que a tarefa de sua responsabilidade iniciará em uma data próxima, por exemplo.

Goldratt (1997) explica que o projeto é, normalmente, medido de acordo com o trabalho ou o investimento realizado em relação ao montante a ser desenvolvido. Portanto, não há distinção entre o trabalho realizado no Caminho Crítico e o trabalho executado em outros caminhos (LECHLER; RONEN; STOHR, 2005; WORLEY, 2005; GIACOMETTI et al., 2007). Este monitoramento pode fazer o gerente de projetos iniciar e continuar sem foco, uma vez que o atraso de um caminho pode ser compensado com o progresso de outro. Isso pode passar a falsa percepção de que o projeto evolui como um todo, mas não necessariamente no Caminho Crítico. O 
problema surge no momento em que os caminhos que foram adiantados precisarão esperar pela finalização dos caminhos atrasados que, por consequência, resultará no atraso do projeto como um todo (RAZ; BARNES; DVIR, 2004; YANG, 2007). Dessa forma, surge a proposta de monitorar o projeto por meio dos pulmões de tempo.

Segundo Goldratt (1997), o monitoramento dos pulmões mantém o foco. Steyn (2000) explica que o risco de atrasos pode ser mensurado pelo consumo dos pulmões. Esta é uma alternativa factível para focar o gerente de projetos. O monitoramento dos pulmões apontará a ocorrência de problemas a serem tratados para a conclusão do projeto (NEWBOLD, 1998; IOANNOU; PAPADOYIANNIS, 2004; LECHLER; RONEN; STOHR, 2005).

Um exemplo quanto à aplicação dos pulmões de tempo pode ser observado na Figura 3. Um pulmão de projeto (PP) está posicionado ao fim do projeto, protegendo-o como um todo (YEO; NING, 2002; LECHLER; RONEN; STOHR, 2005). O pulmão de convergência (PC) garante que a atividade 3 atenderá à sequência 1-2-4 sem atrasos. Por fim, o pulmão de recurso (PR) garante que, ao fim da atividade 2 , o recurso que executará a atividade 4 estará preparado para iniciá-la. O pulmão de recurso é utilizado neste local em função da descontinuidade do recurso executante das atividades, visto que as atividades 1 e 2 são executadas pelo recurso $X$ e a atividade 4 pelo recurso $\mathrm{Y}$.

Goldratt (1997) explica que a Corrente Crítica pode divergir do Caminho Crítico quando há contenção de recursos. A Corrente Crítica tem como objetivo não programar atividades executadas por um mesmo recurso em paralelo, o que, por consequência, elimina a chance de programar atividades que originarão multitarefa (YEO; NING, 2002; LECHLER, RONEN; STOHR, 2005). Goldratt (1997) finaliza explicando que os mesmos princípios devem ser utilizados no ambiente multiprojetos. Deve-se, portanto, identificar o recurso restritivo para o conjunto de projetos e sequenciar as atividades de acordo com a prioridade do projeto (IOANNOU; PAPADOYIANNIS, 2004; AGARWAL; BORCHERS, 2009).

Os passos a serem seguidos na implementação da Corrente Crítica estão resumidamente apresentados na Figura 4.

\begin{tabular}{|c|c|c|c|}
\hline & & \begin{tabular}{l|l} 
Z) & PC \\
\end{tabular} & \multirow[b]{2}{*}{ PP } \\
\hline $1(\mathrm{X})$ & $2(X)$ & $4(Y)$ & \\
\hline \multicolumn{4}{|c|}{ PR } \\
\hline
\end{tabular}

Figura 3. Exemplo dos pulmões de tempo e seu posicionamento. Fonte: Adaptado de Herroelen e Leus (2001).
A seguir se expõe a abordagem do método da Corrente Crítica especificamente para ambientes multiprojetos.

\subsection{Aplicação da corrente crítica no ambiente multiprojeto}

Até aqui, a proposta para implementação da Corrente Crítica, apresentada neste trabalho, focou um único projeto. Porém, em algumas situações, há o desenvolvimento de diversos projetos em paralelo, formando um ambiente multiprojeto. Leach (2005) ressalta a importância do planejamento de projetos no ambiente multiprojeto. $\mathrm{O}$ fato de haver múltiplos projetos na organização tende a deixar a situação complexa e, possivelmente, próxima à inércia, momento no qual os projetos parecem não mais evoluírem (COHEN; MADELBAUM; SHTUB, 2004; LEACH, 2005; AGARWAL; BORCHERS, 2009).

Desta forma, Leach (2005) informa que, em algumas situações nesse tipo de ambiente, os colaboradores trabalharão intensamente, mas os projetos tendem a levar um longo tempo para sua finalização. Além disso, será necessário significativo esforço para gerenciá-los e pode haver a impressão de falta de recursos para finalizar os projetos (LEACH, 2005; WORLEY, 2005). Leach (2005) e Newbold (1998) apresentam propostas semelhantes para o ambiente multiprojeto. Para os fins desse trabalho, a proposta de Leach (2005) é detalhada considerando sua robustez e detalhamento metodológico.

A proposta de Leach (2005) admite ser o recurso restritivo o responsável pela capacidade do sistema. Assim, deve-se iniciar com a identificação do recurso restritivo, o qual ditará o ritmo do sistema (chamado de Tambor) e também deverá ser protegido por um Pulmão de Tempo: o pulmão do tambor (drum buffer) (UMBLE; UMBLE, 2000; AGARWAL; BORCHERS, 2009). Existe, também, o pulmão de capacidade (capacity constraint buffer). Conforme explica Leach (2005), as atividades programadas para o recurso restritivo foram estimadas com tempos médios, portanto, também estão sujeitas a atrasos.

Assim, a proposta é utilizar um pulmão de capacidade entre o conjunto de atividades de cada projeto que necessitar do recurso restritivo (UMBLE; UMBLE, 2000; AGARWAL; BORCHERS, 2009). Isso é necessário para que as oscilações nos tempos das atividades sejam absorvidas por este pulmão de tempo, evitando atrasos nas atividades do projeto seguinte. $\mathrm{O}$ detalhamento da proposta completa de Leach (2005) é apresentado na Figura 5.

A Figura 6, por sua vez, ilustra a proposta de Leach (2005), na qual no projeto "S" pode-se identificar a inserção do pulmão de capacidade (PCA) e o pulmão do tambor (PT), a fim de garantir o sincronismo do recurso restritivo "C" entre os projetos. Para 


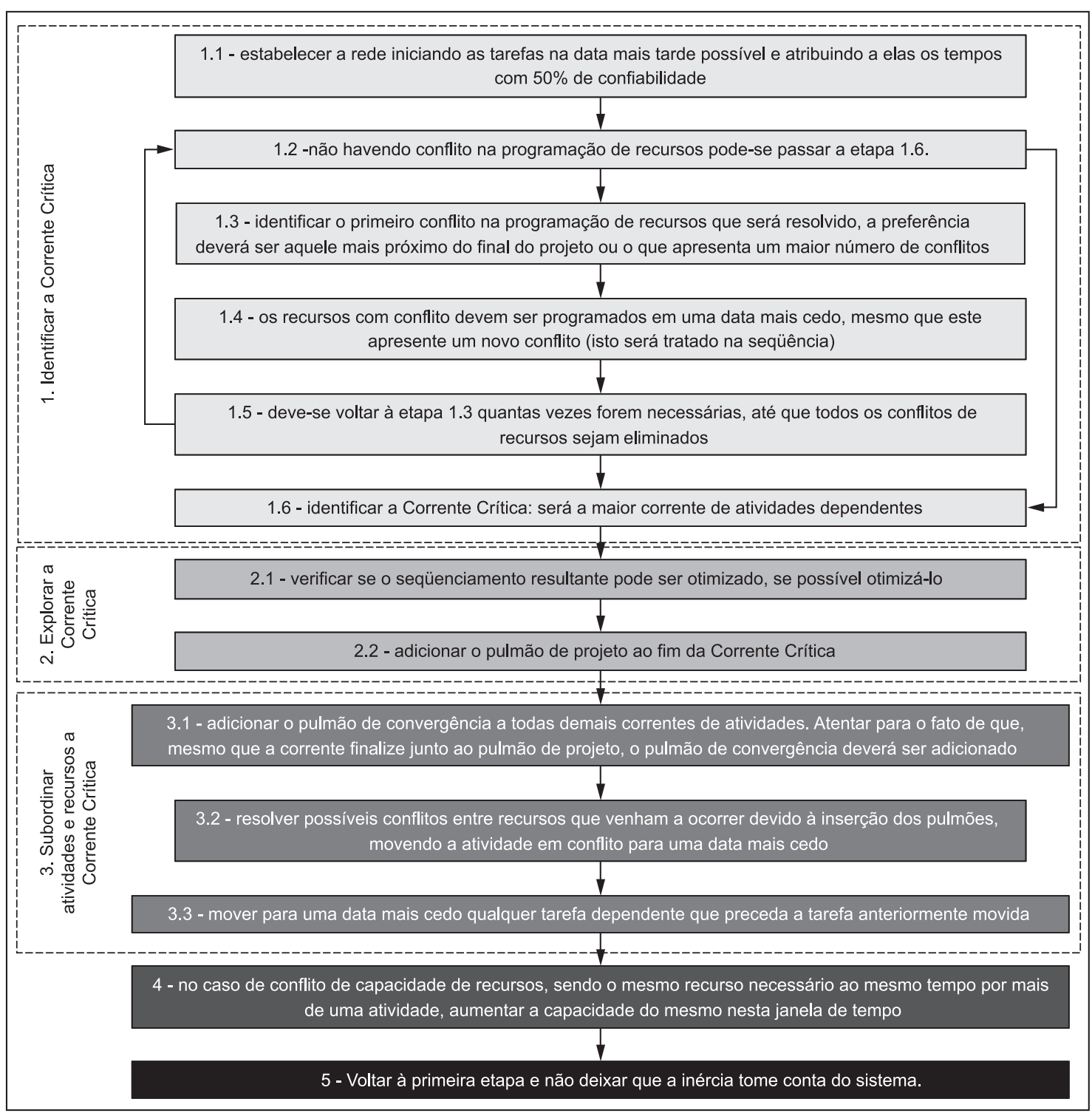

Figura 4. Passos para a implantação da Corrente Crítica. Fonte: Adaptado de Leach (2005).

garantir que o projeto "S" esteja disponível para ser trabalhado por "C" quando este concluir o projeto "R", os recursos "A" e "B" antecedem o início de suas atividades em "S" pela inserção do pulmão do tambor no projeto.

Seguindo a proposição, para garantir que o recurso "C" esteja disponível no tempo planejado para trabalhar em " $\mathrm{T}$ " (o projeto seguinte), é inserido o pulmão de capacidade após sua atividade no projeto "S", que se propõe a garantir que o recurso "C" não se atrasará para trabalhar no projeto seguinte. Observar que os projetos " $T$ " e " $R$ " foram utilizados para mostrar o sincronismo do projeto "S", portanto, não possuem o pulmão de capacidade e o pulmão do tambor, respectivamente.
Conforme exposto por Silva (2010), o PP não deverá ser dimensionado para proteger todas as atividades da corrente crítica do projeto, mas somente aquelas que ainda não estão protegidas pelo PT e pelo PCA. Conforme apresentado por Leach (2005), a sincronização dos projetos com base no recurso gargalo tende a resolver a contenção para a maioria dos recursos, senão para todos. A seguir será evidenciada a abordagem metodológica que sustentou a realização da pesquisa.

\section{Abordagem metodológica}

O presente estudo se caracteriza, em termos de sua natureza (SILVA; MENEZES, 2001), como uma pesquisa aplicada. Essa caracterização ocorre pelo 


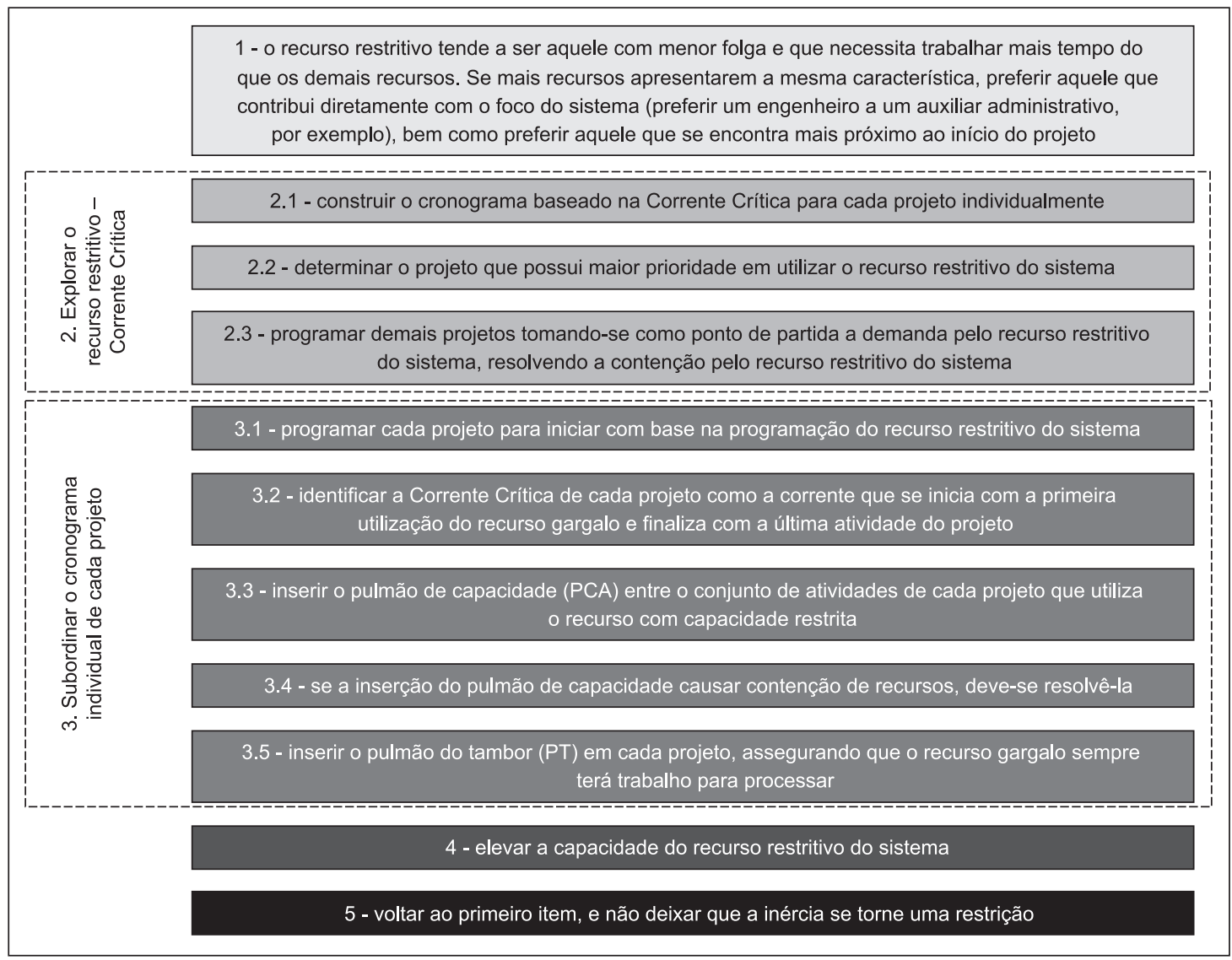

Figura 5. Passos de aplicação da Corrente Crítica no ambiente multiprojetos. Fonte: Adaptado de Leach (2005).

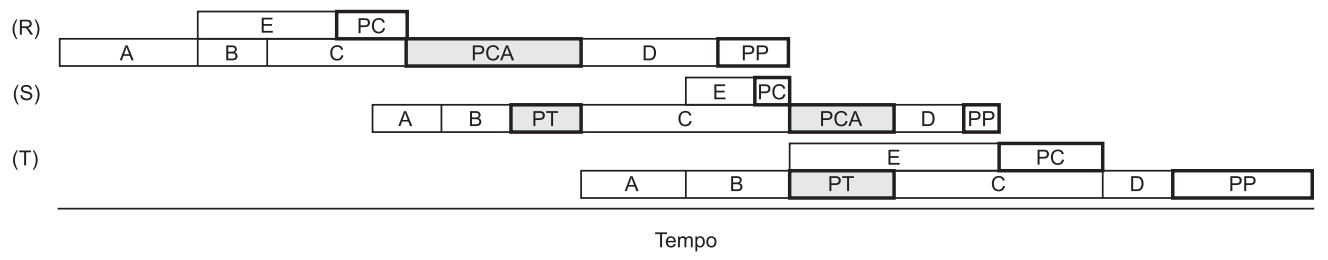

Figura 6. Planejamento multiprojeto conforme Leach (2005). Fonte: Silva (2010).

objetivo de gerar conhecimentos para aplicação prática dirigidos à solução de problemas específicos. Em termos dos objetivos, diversos autores (GIL, 2007; YIN, 2004; SILVA; MENEZES, 2001; VARGAS; MALDONADO, 2001) classificam as pesquisas em: i) descritivas; ii) exploratórias; e iii) explanatórias. Essa pesquisa caracteriza-se por um objetivo exploratório, uma vez que propõe e avalia, crítica e empiricamente (baseado em um caso), uma abordagem para a implantação da Corrente Crítica em ambiente multiprojeto. Portanto, se restringiu ao estudo e proposta de aplicação do método, não se preocupando em descrever a natureza dos problemas presentes na implantação ou as relações causais que implicam no uso da Corrente Crítica em um ambiente multiprojeto.

Nesse sentido, este trabalho, pelo objetivo que se propôs, se caracteriza pela necessidade de uma abordagem qualitativa. O objetivo está relacionado ao ambiente específico em que a construção e, principalmente, a potencial aplicação da abordagem proposta ocorrem. Em situações com essa configuração, diversos autores (SRIVASTAVA; TEO, 2006, SOBH; PERRY, 2006; AMARATUNGA et al., 2002; MANGAN; LALWANI; GARDNER, 2004; NEVES, 1996; GODOY, 1995a, 1995b e 1995c) recomendam o uso de uma abordagem qualitativa.

Dentro da abordagem qualitativa, há diferentes métodos de investigação, entre esses, se encontram os Estudos de Caso (GODOY, 1995b). O Estudo de Caso é um método de investigação que se caracteriza pela análise aprofundada de uma determinada realidade. Segundo Dubé e Paré (2003), corroborado por (MIGUEL, 2007), os Estudos de Caso são apropriados quando o objeto de investigação é complexo; é 
necessária uma visão do todo e o fenômeno estudado não pode ser analisado fora do contexto em que ocorre.

Esse método de investigação também é apropriado nos casos em que é necessária profundidade na pesquisa (DUBÉ; PARÉ, 2003; EISENHARDT, 1989). Além disso, para Ellram (1996), o Estudo de Caso pode ser utilizado para: 1) explorar um determinado assunto ou problema, entendendo-o profundamente; 2) explanar sobre um fenômeno; 3 ) descrever um fenômeno; e 4) predizer características suas. Alguns dos propósitos para o uso do Estudo de Caso, descritos por Ellram (1996) e Eisenhardt e Graebner (2007), justificam a utilização desse método para essa pesquisa. Para a condução do trabalho foram estabelecidos alguns procedimentos. Esses procedimentos estão sintetizados na Figura 7.

Conforme pode ser observado, após o levantamento e análise do referencial, foram estabelecidas as abordagens para implementação da Corrente Crítica para o gerenciamento de um projeto ou de múltiplos projetos. Essas abordagens já foram explicitadas. Paralelamente, foi procedido um levantamento da situação atual no ambiente específico que serviu como lócus da pesquisa. Esse procedimento foi necessário para as adaptações da abordagem proposta ao ambiente específico. Além disso, a análise da situação atual, por meio da construção de uma Árvore da Realidade Atual, constitui uma contribuição indireta do presente trabalho. A Árvore da Realidade Atual (ARA) é uma das ferramentas do Processo de Pensamento da Teoria das Restrições (GOLDRATT, 1991; GOLDRATT, 1994; KIM; MABIN; DAVIES, 2008; LACERDA; RODRIGUES; CASSEL, 2010) que serve para compreender, por meio de relações de efeito-causa-efeito, determinada realidade, complexa, ou não. A escolha da ARA ocorreu pela possibilidade de compreender os problemas e suas relações de efeito-causa-efeito que contribuem para o atraso nos projetos.

Para a análise da situação atual, foram procedidas entrevistas e o levantamento de documentos. Contou-se também com a observação direta por parte de um dos autores do estudo. O objetivo foi identificar as possíveis causas da incidência de atraso nos projetos. Para reduzir o possível viés na análise, a Árvore da Realidade Atual foi escrutinada pelos outros autores, utilizando-se das entrevistas para aumentar a validade interna da pesquisa (MENTZER; FLINT, 1997). Os documentos levantados foram os cronogramas de um determinado grupo de empreendimentos, os quais se encontravam na fase de projeto executivo (em andamento ou concluído), sendo a finalidade verificar a incidência de atraso nestes, justificando este estudo. As entrevistas foram realizadas com engenheiros coordenadores de projetos, pois são estas as pessoas que conduzem e são responsáveis pelos projetos. Foram entrevistados oito engenheiros coordenadores de projetos ao todo, que possuem entre dois e vinte anos de empresa. Destaca-se que quatro engenheiros coordenadores de projetos possuem especialização em gerenciamento de projetos. Embora estes possuam experiência no cargo, a tarefa de gerenciar projetos é recente, tendo aproximadamente quatro anos. As entrevistas foram transcritas e se procedeu à análise de conteúdo, conforme recomendações de Bardin (2001) para identificação dos problemas (efeitos indesejados) da ARA.

De posse desses elementos, se procurou, cotejando a fonte teórica com a análise do caso concreto, elaborar e adaptar a proposta de implementação da Corrente Crítica em um ambiente multiprojeto. No caso específico, as adaptações ocorreram para

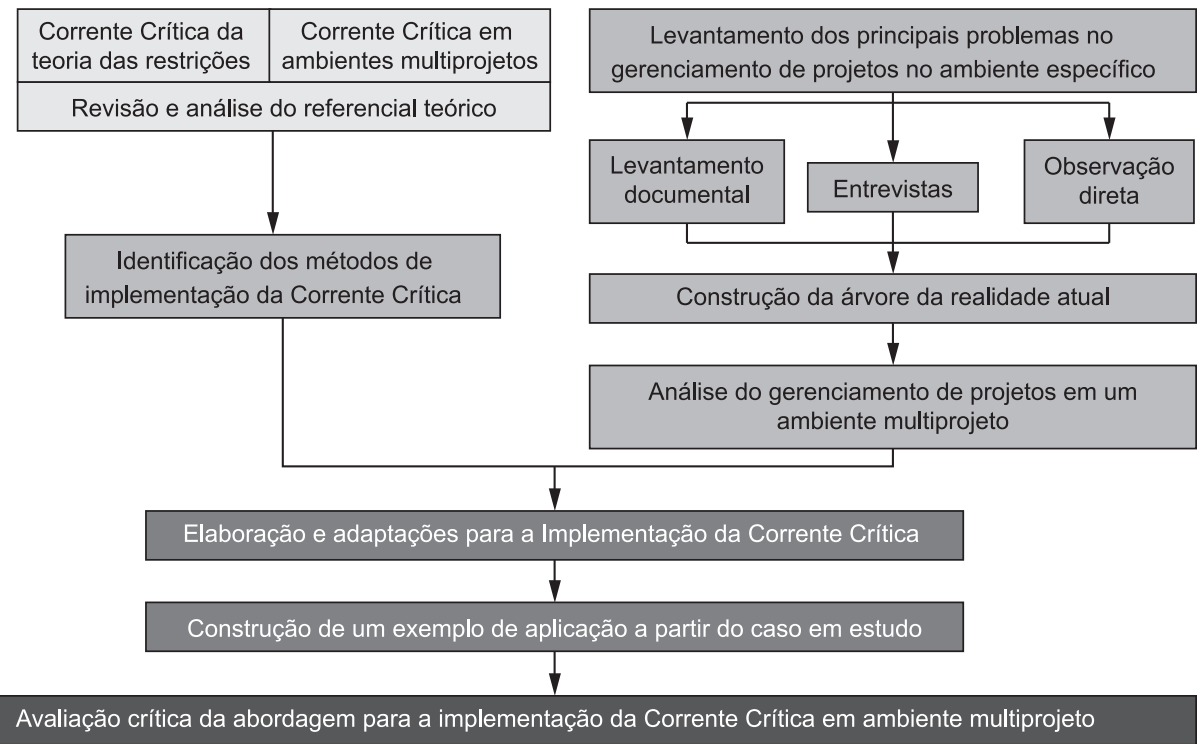

Figura 7. Procedimentos metodológicos. Fonte: Elaborado pelos autores. 
adequar a abordagem ao ambiente de estudo, no caso, o departamento de engenharia de uma refinaria de petróleo. A descrição desse ambiente e sua contextualização serão realizadas na sequência.

A avaliação da proposta diante do caso teve dois objetivos centrais. O primeiro foi avaliar as possíveis implicações da adoção da Corrente Crítica em um ambiente multiprojetos. O segundo objetivo está vinculado ao processo de reflexão crítica que procura estabelecer melhor as contribuições e, principalmente, as limitações da presente abordagem. Essa seção específica também será discutida ao final do trabalho. A seguir se contextualiza a organização em que a pesquisa foi realizada.

\section{$4 \mathrm{O}$ caso estudado}

O departamento de Engenharia da refinaria tem como atividade fim o desenvolvimento e execução de empreendimentos, compreendendo desde a concepção até a entrega para a área cliente. Estes empreendimentos são voltados à manutenção e adequação operacional das unidades de processo da refinaria. O ciclo de vida de um empreendimento pode ser dividido em três fases, conforme o Quadro 2.

A estrutura da Engenharia e seus recursos são divididos por disciplinas, cada uma responsável por uma especialidade, as quais estão estruturadas conforme a Figura 8 . Pode-se verificar que a gerência conta com o apoio do Planejamento e do ADOC (Atividade de Documentação). Respondem à gerência de engenharia as demais disciplinas, agrupadas nas etapas que compõem o empreendimento.

Quadro 2. Fases do ciclo de vida de um empreendimento.

\begin{tabular}{|c|c|}
\hline Fase & Descrição \\
\hline $\begin{array}{c}\text { Projeto } \\
\text { básico }\end{array}$ & $\begin{array}{c}\text { Onde ocorre a concepção do } \\
\text { empreendimento. O projeto básico } \\
\text { define o que deverá ser feito }\end{array}$ \\
\hline $\begin{array}{c}\text { Projeto } \\
\text { executivo }\end{array}$ & $\begin{array}{c}\text { Etapa em que o projeto é detalhado } \\
\text { a fim de viabilizar sua execução. O } \\
\text { projeto executivo define como fazer }\end{array}$ \\
\hline $\begin{array}{c}\text { Construção e } \\
\text { montagem }\end{array}$ & $\begin{array}{c}\text { Etapa em que o empreendimento é } \\
\text { executado, materializando-se }\end{array}$ \\
\hline
\end{tabular}

Fonte: Elaborado pelos autores.
As etapas de projeto básico, projeto executivo e construção e montagem, em geral, ocorrem em sequência, com exceções que acontecem para agilizar a execução. Na sequência, é detalhada a fase de projeto executivo, visto ser ela o foco deste estudo.

\subsection{O projeto executivo}

O projeto executivo é a etapa em que se detalha a concepção estabelecida no projeto básico, para possibilitar sua execução na etapa de construção e montagem. É o momento em que o empreendimento requer o envolvimento de diferentes especialidades, havendo um trabalho em paralelo entre elas. Além disso, há momentos de interface em função da necessidade das especialidades dependerem de requisitos mutuamente. Este fluxo é representado na Figura 9.

Cada especialidade que compõe o projeto executivo é liderada por um coordenador de disciplina, e ela é composta por engenheiros, técnicos, projetistas e desenhistas. Cada projeto executivo é liderado por um coordenador, em geral, um engenheiro da especialidade com maior familiaridade com o escopo do projeto. Próximo do início, o projeto executivo é detalhado com o apoio da equipe de planejamento. Este é um processo não padronizado, no qual os prazos que constituirão o cronograma são, geralmente, estipulados por especialidade (engenheiro e colaboradores). As atividades são planejadas para iniciarem na data mais cedo possível. Os tempos são, dentro do possível, separados por atividade e os recursos envolvidos têm sua capacidade dividida entre os projetos. A base histórica, empírica, é utilizada para divisão das atividades e os tempos planejados.

Os projetos que estão na etapa do projeto executivo são executados paralelamente. O progresso em cada projeto é realizado em função da prioridade estabelecida pela refinaria e repassada aos coordenadores. A prioridade dos projetos é definida de acordo com a contribuição que o projeto exerce em fatores, como: i) retorno financeiro; ii) confiabilidade operacional; iii) operabilidade da planta; iv) atendimento à legislação; v) meio ambiente, saúde e segurança. A priorização é definida conjuntamente com as gerências

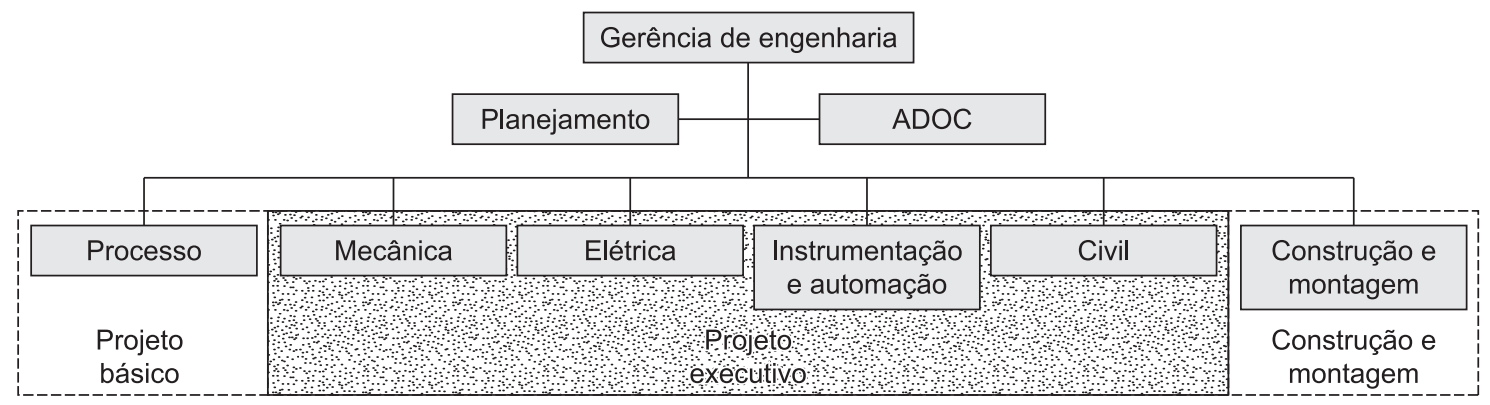

Figura 8. Estrutura da Engenharia da refinaria em questão. Fonte: Silva (2010). 


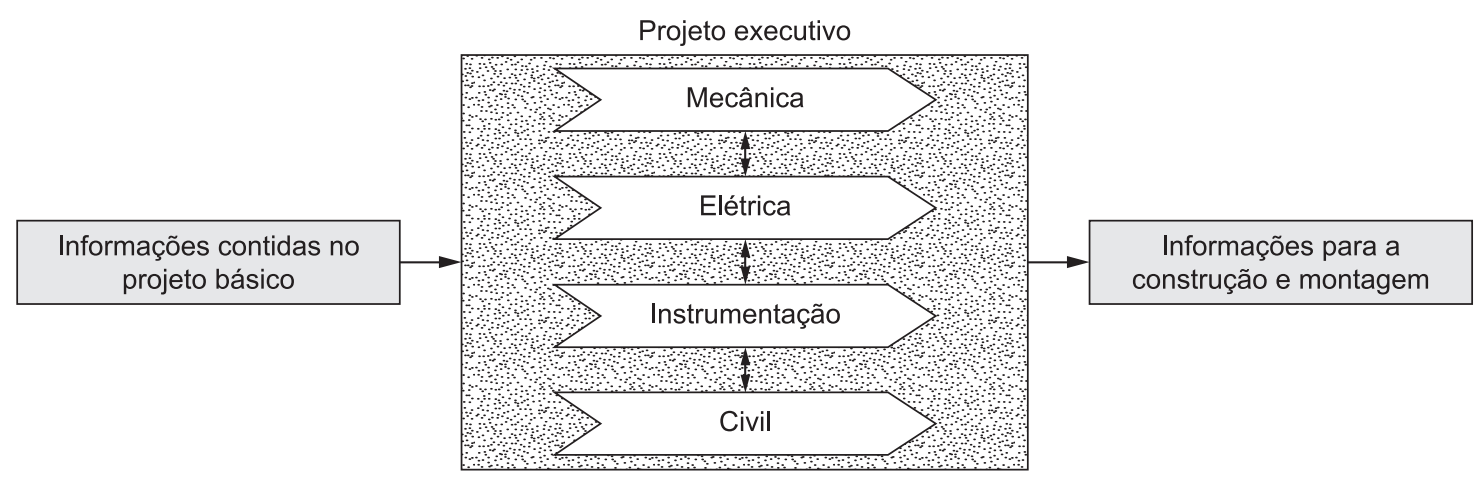

Figura 9. Fluxo destacando as disciplinas do projeto executivo. Fonte: Silva (2010).

solicitantes dos projetos. Contudo, é estabelecida pelo comitê da avaliação de empreendimentos, composto por membros da direção da empresa. Os empreendimentos estão expostos a alterações a partir do inicialmente planejado uma vez que ocorrem mudanças de prioridade após o seu início.

Alterações na sequência de execução dos projetos são gerenciadas em conjunto pelas especialidades e pelo Planejamento. O líder de cada especialidade e o coordenador do projeto definem a forma com que as atividades serão adaptadas à priorização, fazendo o replanejamento dos recursos. A interação que ocorre entre as especialidades é breve, restringindo-se à troca de informações de maneira informal.

Com a finalização, por parte das disciplinas, encerra-se o projeto executivo. Cada disciplina envolvida tem como entrega um conjunto de documentos contendo memoriais descritivos, relatórios e desenhos. O pacote de trabalho de cada especialidade é independente das demais, exceto pela dependência que pode haver em algumas situações. O gerenciamento do projeto executivo é realizado pelo planejamento da Engenharia. O coordenador do projeto é responsável pelo seu andamento e pelas ações referentes a ele. O gerenciamento do tempo dos projetos ocorre sobre os cronogramas estabelecidos.

Os recursos permanecem, em sua totalidade, com atividades em paralelo de diferentes projetos. O desenvolvimento de atividades em paralelo é uma prática da empresa. Isso decorre, principalmente, da busca pelo aumento de produtividade dos recursos envolvidos. $\mathrm{O}$ indicador utilizado para acompanhar o progresso do projeto é composto pela data de conclusão prevista e o porcentual concluso. Há uma distinção por especialidade e suas diversas subtarefas, no entanto, a análise ocorre sobre a porcentagem do projeto.

A atualização dos cronogramas ocorre quinzenalmente. Nessas atualizações é relatada a porcentagem concluída do projeto por especialidade. Essa informação é baseada na percepção dos colaboradores, sem a real distinção do avanço das atividades planejadas.

\subsection{Avaliação do atual processo de gerenciamento de projetos}

As informações obtidas na etapa de levantamento de dados estão na ARA apresentada na Figura 10. A partir da análise da ARA, pode-se observar que uma parte significativa dos problemas percebidos é advinda de cinco causas raiz. Primeiro, inexiste uma sistemática adequada para identificação e tratamento das necessidades da refinaria (01). Esta é uma causa externa à área de Engenharia e interna à refinaria. Refere-se à inexistência de um estudo que leve em conta o conjunto de necessidades da refinaria.

Segundo, ao serem iniciados, os projetos são planejados (10), uma prática que objetiva permitir acompanhar o desenvolvimento dos projetos, que se torna uma referência para determinar se o projeto está, entre outros fatores, cumprindo seu cronograma. Desta forma, os projetos sempre são planejados ao iniciarem, o que cria uma referência para que se possa afirmar que eles, em determinadas situações, atrasam. Terceiro, os projetos executivos apresentam proposições inovadoras (12), decorrência do fato de que os projetos não apresentam uma solução comum e conhecida. Portanto, representam um desafio que requer esforço de desenvolvimento projetual e tecnológico. Quarto, o gerenciamento de projetos não é uma prática na empresa (17), sendo essa uma causa interna ao setor de Engenharia, associada às práticas da empresa e considerada um paradigma que se perpetua por inércia. Por fim, associa-se produtividade com quantidade de trabalho em desenvolvimento (2). Fator oriundo da intenção de se alcançar uma maior produtividade, em que a ação resultante visa a inexistência de qualquer ociosidade no sistema, que se traduz na rotina de, em qualquer momento que houver descontinuidade em uma atividade, se iniciar imediatamente outra atividade, o que resulta em uma maior quantidade de trabalho em execução. Dessa forma, imagina-se que, em havendo uma maior quantidade de trabalho em desenvolvimento, o sistema está sendo mais produtivo. Essa mesma percepção remete à atitude de iniciar projetos o 


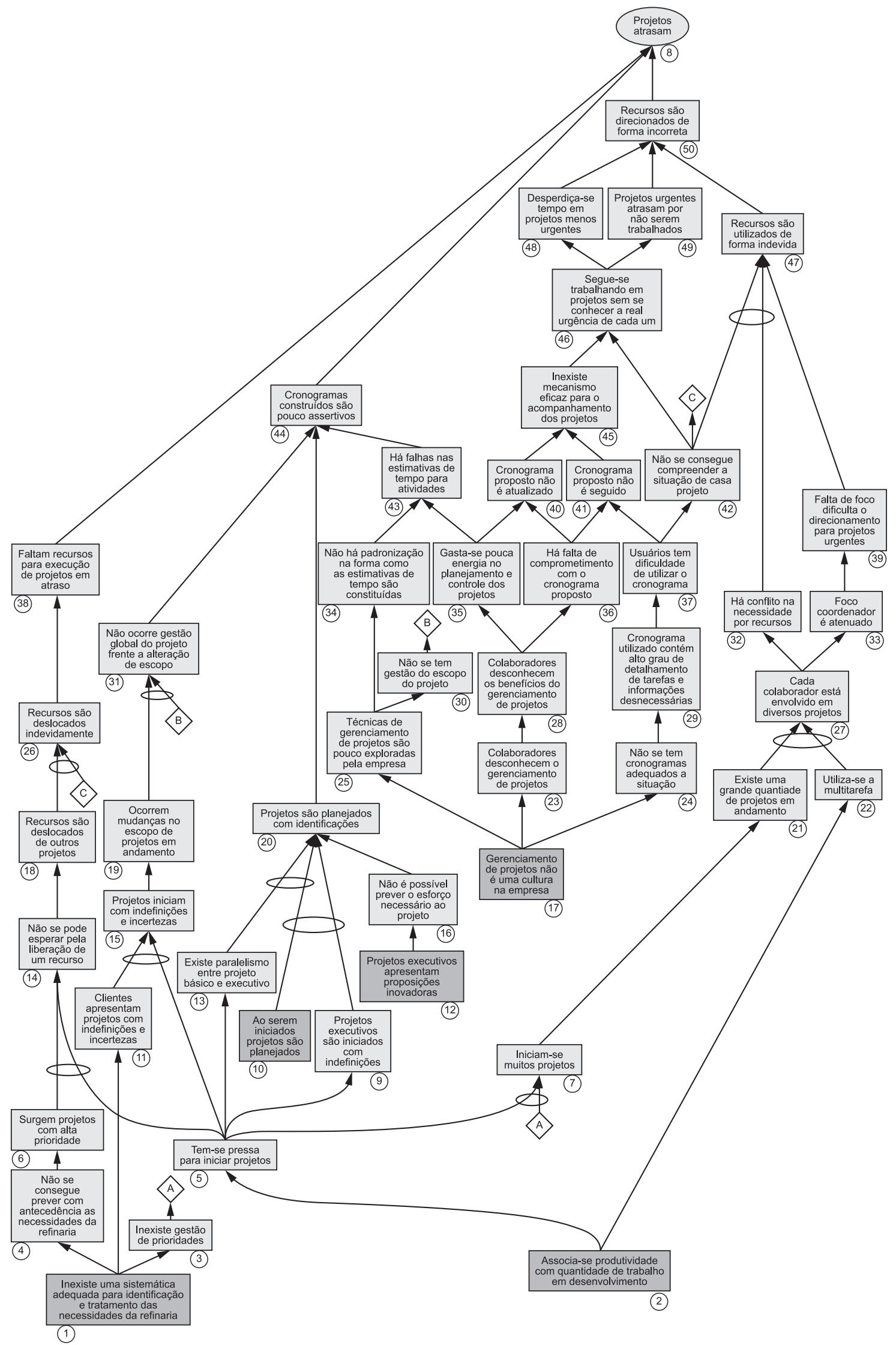

Figura 10. ARA: Causas que levam os projetos a atrasar. Fonte: Silva (2010). 
mais breve possível, implicando a multitarefa e suas consequências.

Uma das possibilidades de melhoria é a adoção da Corrente Crítica para mitigar os problemas (efeitos indesejados) por meio das causas raiz 17 e 2 . O fato de haver uma cultura de gerenciamento de projetos não garante a inexistência de deficiências. Algumas dessas deficiências podem ser reduzidas caso a cultura de gerenciamento de projetos incorpore conceitos da Corrente Crítica, por exemplo. A associação de produtividade com quantidade de trabalho em desenvolvimento, nesse caso, seria abandonada se a cultura de gerenciamento de projetos adotada contemplasse os preceitos da Corrente Crítica.

Outras causas raiz necessitariam de outras abordagens ou aplicações tecnológicas e, portanto, fogem do escopo desse trabalho. Porém, alguns dos efeitos indesejáveis dessas causas raiz poderiam ser mitigados com a utilização da Corrente Crítica, o que é importante, visto que algumas causas raiz não poderão ser eliminadas. A seguir é apresentada a proposta para implementação da Corrente Crítica no ambiente específico.

\section{Proposta de implementação da corrente crítica}

A proposta de implementar a Corrente Crítica no caso estudado contempla uma determinada carteira de projetos. A visão geral desta proposta é apresentada na Figura 11. Primeiro é necessário realizar a definição das atividades. Esta é uma etapa atualmente existente no caso estudado, porém informal e não padronizada. Deve-se criar uma padronização na definição das atividades ou de conjuntos de atividades. Além disso, deve-se estabelecer uma sistemática que permita identificar, padronizadamente, as atividades necessárias para se produzir as entregas requeridas. Essa padronização poderá ser benéfica para futuras comparações e para o aprendizado baseado no histórico. Reconhece-se que proposições inovadoras não serão contempladas, porém os benefícios para as demais situações não são afetadas.
O segundo passo é a Construção das estimativas de tempo. Esta etapa objetiva atingir melhores resultados comparativamente ao alcançado por estudos superficiais. Pretende-se, a partir das definiçõoes, construir uma base de informações para a construção de cronogramas. Primeiramente, esta base contará com estimativas obtidas a partir da análise inicial e, posteriormente, será aperfeiçoada pelos dados históricos e pelo aprendizado desenvolvido. Conforme premissa da Corrente Crítica, as estimativas dessas estimativas deverão ser desafiadoras.

O terceiro passo é a Programação de recursos. Nesse sentido, procura-se eliminar a multitarefa, conforme proposto pela Corrente Crítica. Os recursos não serão programados para desenvolver atividades em diferentes projetos, paralelamente, em especial os níveis operacionais (desenhistas, projetistas, entre outros). Entende-se que os engenheiros, por se envolverem em atividades com menor duração, podem coordenar diferentes atividades em paralelo. Também, recomenda-se que a transição do recurso entre atividades ocorra após o recurso concluir as atividades ou determinada etapa desta. Assim se espera uma redução na perda de foco entre a pausa em uma atividade e o início de outra

A quarta etapa é a utilização e o dimensionamento dos pulmões de tempo. Esta proposta visa possibilitar um monitoramento mais efetivo e preciso dos projetos, o qual será viabilizado por meio do monitoramento dos pulmões do projeto. Conforme Silva (2010), recomenda-se que o dimensionamento dos pulmões de tempo seja coerente com as atividades e estimativas de tempo propostas, sendo mais conservador em fase inicial de experimentação. O quinto passo é a construção dos cronogramas individuais, segundo o qual o cronograma de cada projeto deve ser construído alinhado com a lógica da Corrente Crítica.

$\mathrm{Na}$ etapa seguinte, deve-se identificar o recurso gargalo: o recurso com maior demanda pelo sistema. A base para a decisão deverão ser as atividades planejadas para os projetos e suas estimativas de tempo, conforme proposto anteriormente pelos itens 1 e 2 . Sugere-se que, a fim de facilitar o processo,

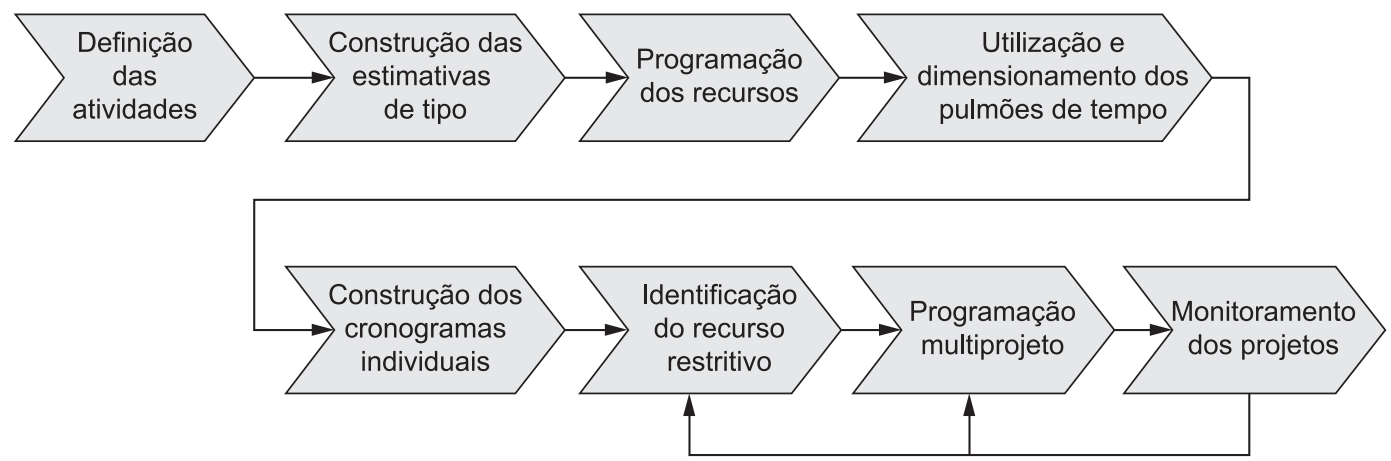

Figura 11. Visão geral da proposta de implementação da Corrente Crítica. Fonte: Elaborado pelos autores. 
o gargalo seja definido como sendo certo grupo de recursos que se assemelham. Assim, propõe-se que, para cada disciplina, sejam utilizados dois grupos (pool de recursos): um envolvendo atividades de engenharia, composto por engenheiros, e outro envolvendo atividades técnicas, composto por técnicos de projeto, projetistas e desenhistas (visto serem atividades semelhantes).

O sétimo passo consiste na programação multiprojeto, na qual se deve utilizar a proposta de programação multiprojeto apresentada por Leach (2005), para considerar a restrição do grupo de projetos envolvido. O oitavo, e último, passo é o monitoramento dos projetos, o qual deverá ocorrer a partir do monitoramento dos pulmões do projeto, que deverá permitir um controle mais efetivo e focado.

\subsection{Adaptações do método proposto ao objeto de estudo}

O presente estudo identificou pontos em que a proposta pode ter sua aplicação questionada ou não ser integralmente aplicável à realidade estudada. $\mathrm{O}$ primeiro questionamento refere-se à dedicação integral dos recursos. Percebe-se ser impraticável a dedicação integral de todos os recursos. Entende-se que, recursos cujas atividades envolverão $100 \%$ de seu tempo por um longo período, podem se dedicar exclusivamente a uma única atividade. Porém, recursos cujas atividades envolvem um longo período, mas não dedicação integral durante esse período, não deverão permanecer dedicados a esta atividade, sendo assim recomendado o seu envolvimento em outra atividade em paralelo.

O segundo questionamento ocorre sobre a utilização do pulmão de convergência. Visto que cada disciplina, ao final do projeto, faz a entrega independente dos outros "pacotes" de trabalho, questiona-se a forma como o pulmão de convergência será utilizado. Se este preceder o pulmão de projeto, conforme mostra a Figura 12a, a corrente não crítica passa a ter um período excessivo de segurança (SILVA, 2010), visto estar ela sendo protegida pelo somatório do tempo do pulmão de projeto com o tempo do pulmão de convergência. Assim, surge a proposta de utilizá-lo de forma a manter o final programado da atividade da corrente não crítica alinhado com o da final programado da atividade da Corrente Crítica, conforme Figura 12b. Ou ainda, de maneira arrojada, programar as atividades para manter alinhado o término dos pulmões, conforme a Figura 12c. Sugere-se a adoção do planejamento conforme apresentado pela Figura 12b para reduzir o excesso de segurança apresentado na Figura 12a e não ser tão arrojado quanto o exemplo da Figura 12c.

Segue-se questionando a redução das estimativas de tempo, visto que não se julga adequada a proposta de redução dos tempos estimados para as atividades em $50 \%$. Percebe-se existir estimativas com determinada

\begin{tabular}{|l|r|r|r|}
\cline { 2 - 4 } \multicolumn{2}{|c|}{$3(\mathrm{Z})$} & $\mathrm{PC}$ & \\
\hline $1(\mathrm{X})$ & $2(\mathrm{X})$ & $4(\mathrm{X})$ & $\mathrm{PP}$ \\
\hline \multicolumn{3}{|c|}{ Tempo } \\
\hline \multicolumn{3}{|c|}{} \\
\hline
\end{tabular}

\begin{tabular}{|l|r|r|r|}
\cline { 3 - 4 } \multicolumn{2}{|c|}{} & $3(\mathrm{Z})$ & $\mathrm{PC}$ \\
\hline $1(\mathrm{X})$ & $2(\mathrm{X})$ & $4(\mathrm{X})$ & $\mathrm{PP}$ \\
\hline \multicolumn{3}{|c|}{ Tempo }
\end{tabular}

(c)

\begin{tabular}{|l|c|r|c|c|}
\multicolumn{2}{|c|}{} & $3(\mathrm{Z})$ & $\mathrm{PC}$ \\
\hline $1(\mathrm{X})$ & $2(\mathrm{X})$ & $4(\mathrm{X})$ & $\mathrm{PP}$ \\
\hline \multicolumn{3}{|c}{ Tempo }
\end{tabular}

Figura 12. Posicionamento do pulmão de convergência. Fonte: Silva (2010).

margem de segurança, o que justificaria essa redução, mas não necessariamente em $50 \%$. Também existem estimativas otimistas, as quais não assumiriam qualquer redução na sua estimativa de tempo. Sugere-se um estudo aprofundado sobre o trabalho envolvido em cada atividade antes de propor a redução das estimativas de tempo.

Por fim, ao propor esta aplicação da Corrente Crítica, questiona-se sua funcionalidade no ambiente em questão. Segundo Dass e Steyn (2006), o presente método seria mais apropriado em situações em que um recurso estaria relativamente mais sobrecarregado que os demais, ou seja, no qual a demanda de trabalho não estaria balanceada. No entanto, não se exclui a possibilidade de obter bons resultados em uma situação com demanda balanceada. Dass e Steyn (2006) citam, ainda, que, no caso de todos os recursos terem uma alta carga de trabalho, o problema deve estar na seleção dos empreendimentos. Na falta de base empírica para afirmar sobre o balanceamento da demanda de trabalho, entende-se que a aplicação do método poderá resultar em resultados positivos indiferentemente da situação do ambiente e que isto mantém a aplicabilidade do método concisa. Porém, ressalta-se a necessidade de melhor avaliar a seleção de projetos no caso de todos os recursos estarem sobrecarregados.

\subsection{Avaliação crítica da proposta de implementação}

Aqui serão abordadas e discutidas as premissas propostas pelo método da Corrente Crítica e sua 
aplicabilidade ao objeto de estudo. O objetivo é apresentar os possíveis benefícios alcançados, os quais são apresentados a seguir.

A primeira premissa a ser discutida é o reconhecimento da capacidade limitada de recursos, um diferencial da Corrente Crítica. Essa medida pode melhor adequar a programação das atividades dos projetos. No caso estudado, pode contribuir para mitigar as situações em que ocorre a conflitante necessidade por recursos e a atual existência de falhas nas estimativas de tempo para atividades. Isso pode, por vezes, ocorrer devido a conflitos existentes na programação de recursos.

A segunda premissa trata do início das atividades na data mais tarde possível, a qual pode otimizar o sistema no sentido de reduzir os mecanismos de desperdício de tempo. Também pode contribuir, para o caso estudado, no sentido de melhorar o foco do coordenador do projeto. Isso decorre do fato de que os recursos não estarão envolvidos em uma atividade em um momento desnecessário e, portanto, essa atividade não necessitará ser monitorada. Outra possível contribuição é no sentido de haver menor risco de retrabalho no caso de ocorrer alguma mudança nos projetos.

Há, ainda, a questão de eliminar a multitarefa. Conforme apresentado, o uso da multitarefa pode resultar no aumento do lead time dos projetos. Assim, a proposição do método de não praticar a multitarefa, ou restringi-la, pode trazer algumas vantagens ao caso estudado, além da benéfica redução do lead time dos projetos. A redução de lead times contribuirá para um sistema dinâmico, em que o surgimento de projetos prioritários será atendido em menor tempo e sem a necessidade de deslocamento de recursos de outros projetos, evitando, consequentemente, atraso nestes outros projetos.

A discussão segue tratando da adição de segurança às estimativas de tempo. No caso estudado, não há uma formal adição de segurança aos projetos, o que leva a crer que existe certa segurança adicionada a cada atividade empiricamente. A presente situação tem resultados negativos, pois contribui para mecanismos de desperdício de tempo como a Síndrome do Estudante e a Lei de Parkinson, bem como para o desperdício de avanços. Essa segurança pode ainda ser insuficiente para suprimir a incerteza inerente a certas atividades, o que inevitavelmente leva o projeto a atrasar. A vantagem vislumbrada é passar a utilizar tempos enxutos para as atividades e trabalhar com toda a segurança necessária ao final do projeto, pois as oscilações que ocorrerão nas atividades se compensarão, e um menor tempo de segurança será necessário.

Por fim, tem-se a questão do controle do projeto, atualmente realizado pelo percentual do total de trabalho executado. Conforme discutido nas proposições do método da Corrente Crítica, esse procedimento não garante que esta mesma evolução tenha ocorrido onde realmente deveria (na corrente crítica do projeto), o que resulta em uma falsa percepção quanto à evolução do projeto. A proposição apresentada é de se monitorar o projeto por meio dos pulmões de tempo, conhecendo-se apenas a data prevista para o término do projeto e a proporção entre a evolução de cada corrente e o consumo do respectivo pulmão, possibilitando um monitoramento mais seguro, focado e eficaz. Essa proposição garante que a evolução do projeto esteja alinhada com o cronograma proposto, bem como possibilita tomar medidas preventivas ao atraso, permitindo reconhecê-lo antes que este se torne uma realidade no projeto.

\section{Conclusão}

Este trabalho se originou da necessidade de melhor gerenciar projetos no ambiente estudado junto a uma proposta de estudo da aplicação da Corrente Crítica. Seu desenvolvimento se deu a partir do estudo do ambiente em questão, no qual se pôde analisar a aplicabilidade da Corrente Crítica e vislumbrar os ganhos passíveis de serem atingidos com a sua utilização.

A análise a qual se chega com o desenvolvimento deste trabalho mostra que o método da Corrente Crítica possui contribuições diversas para o caso estudado, dentre as quais se destaca a possibilidade de maior assertividade dos cronogramas dos projetos. Também se destaca a possibilidade de execução de um menor número de projetos em paralelo, o que resulta em um menor lead time para os projetos e uma mais constante possibilidade de processamento de novos projetos, um benefício estratégico a ser alcançado pelo sistema com a implementação da Corrente Crítica. Assim, tem-se a possibilidade de um sistema mais dinâmico atender a demandas de clientes de forma mais ágil. Executar projetos de forma mais rápida também poderá reduzir problemas oriundos da realidade que se tem em diferentes períodos, como a disponibilidade financeira que se pode surgir na execução de determinado projeto no período corrente, mas que, em função de alguma restrição, pode inviabilizar sua execução em um período futuro, por exemplo. Nesta situação, uma maior agilidade pode garantir que o projeto seja executado no ano corrente e afastar a possibilidade de ele ser suspenso ou cancelado.

Como se pode esperar, o método proposto requer mudanças no ambiente estudado, assim como adaptações ao seu conteúdo, sendo que algumas delas podem ser consideradas mais brandas e outras mais bravas, especialmente em se tratando de mudanças que envolvem cultura e os escalões mais altos da empresa. 
Entre os benefícios que se vislumbra alcançar, tem-se o desenvolvimento de um cronograma mais realista e, consequentemente, mais assertivo, o desenvolvimento de projetos executivos com um menor lead time, um sistema mais dinâmico e mais flexível que permite haver mudanças no escopo do projeto até uma data mais tarde, sem prejuízos ao cronograma, um produto final de maior qualidade (já que, na maior parte do tempo, os recursos estarão dedicados a uma única tarefa, ou ao menos a um menor número de tarefas), e um controle mais efetivo do desenvolvimento dos projetos.

$\mathrm{O}$ presente estudo identificou alguns fatores críticos na aplicação da Corrente Crítica, sendo eles: a aceitação pela Gerência e Direção da empresa; a compreensão e aceitação pelos colaboradores envolvidos; a conscientização e envolvimento de colaboradores; a capacitação dos coordenadores de projeto e dos coordenadores de disciplina; o monitoramento e análise dos resultados obtidos; e a utilização dos pulmões de projeto.

Também foram identificadas algumas necessidades de adaptação da Corrente Crítica para o caso estudado, sendo elas: a necessidade de agrupamento de atividades em um pool de recursos; a necessidade de flexibilização das estimativas de tempo em função da experiência e produtividade de cada recurso; a não utilização de todos os pulmões de tempo propostos; e a permanência da multitarefa oriunda da interação entre disciplinas.

Como avaliação final, considera-se o método proposto satisfatoriamente aplicável ao caso estudado. A Corrente Crítica pode contribuir para com o gerenciamento de projetos no caso estudado. Além disso, se verificam, na literatura, poucos estudos que tratam em específico do ambiente multiprojetos, em geral, e da implementação da Corrente Crítica nesse ambiente, em particular. Nesse sentido, este trabalho, ao mesmo tempo que procura contribuir para esse tipo de conhecimento em gerenciamento de projetos, chama a atenção para a necessidade de maiores estudos. Este trabalho proporcionou o desenvolvimento de um maior conhecimento no que se refere à Corrente Crítica, bem como poderá adicionalmente contribuir com a aplicação prática da proposta apresentada e sua respectiva análise.

\section{Referências}

AGARWAL, A.; BORCHERS, A. Managing Multiple Projects and Departmental Performance Using Buffer Burn Index. International Journal of Global Management Studies, v. 1, n. 3, p. 1-18, 2009.

AMARATUNGA, D. et al. Quatitative and Qualitative Research in the built environment: application of "mixed" research approach. Work Study, v. 51, n. 1, p. 17-31, 2002. http://dx.doi.org/10.1108/00438020210415488

BARBALHO, S. C. M. et al. Rompendo obstáculos para a implantação de escritório de projetos em empresa de base tecnológica. Gestão \& Produção, v. 18, n.3, p. 435-449, 2009.

BUDD, C. S.; CERVENY, J. A critical chain project management primer. In: COX III, J. F.; SCHLEIER JUNIOR, J. G. Theory of Constraints Handbook. McGraw-Hill, 2010.

COHEN, I.; MADELBAUM, A.; SHTUB, A. Multi-Project Scheduling and Control: A process-based comparative study of the Critical Chain Methodology and some alternatives. Project Management Journal, v. 35, n. 2, p. 39-50, 2004.

DASS, S.; STEYN, H. An exploratory assessment of project duration in multiple-project schedules where resources are allocated by the theory of constraints method. Journal of Industrial Engineering, v. 17, p. 39-54, 2006.

DUBÉ, L.; PARÉ, G. Rigor in Information Systems Positivist Case Research: Current Practices, Trends and Recommendations. MIS Quaterly, v. 27, n. 4, p. 597-635, 2003.

EISENHARDT, K. M. Building theories from case study research. Academy of Management Review, v. 14, p.532-550, 1989.

EISENHARDT, K. M.; GRAEBNER, M. E.; Theory Building from Cases: Opportunities and Challenges. Academy of Management Journal, v. 50, n. 1, p. 25-32, 2007. http://dx.doi.org/10.5465/AMJ.2007.24160888

ELLRAM, L. M. The use of the case study method in logistics research. Journal of Business Logistics. Arizona, v. 17, n. 2, p. 93-138, 1996.

GIACOMETTI, R. A. et al. Aplicação do earned value em projetos complexos - um estudo de caso na EMBRAER. Gestão \& Produção, v. 14, n. 3, p. 595-607, 2007.

GIL, A. C. Métodos e técnicas de pesquisa social. São Paulo: Atlas, 2007.

GODOY, A. S. Introdução à Pesquisa Qualitativa e suas possibilidades, RAE - Revista de Administração de Empresas, v. 35, n. 2, p. 65-71, 1995 a.

GODOY, A. S. Pesquisa Qualitativa - Tipos Fundamentais. RAE - Revista de Administração de Empresas, v. 35, n. 3, p. 20-29, 1995 b.

GODOY, A. S. A Pesquisa Qualitativa e seu uso em Administração de Empresas. RAE - Revista de Administração de Empresas, v.35, n.4, p.65-71, 1995c.

GOLDRATT, E. M. Haystack Syndrome. Boca Raton: North River Press, 1991.

GOLDRATT, E. M. It's not a luck. Boca Raton: North River Press, 1994.

GOLDRATT, E. M. Critical Chain. Boca Raton: North River Press, 1997.

HERROELEN, W.; LEUS, R. On the merits and pitfalls of critical chain scheduling. Journal of Operations Management, n. 19. p. 559-577, 2001. http://dx.doi. org/10.1016/S0272-6963(01)00054-7

HERROELEN, W.; LEUS, R.; DEMEULEMEESTER, E. Critical Chain Project Scheduling: Do not oversimplify. Project Management Journal, v. 33, n. 4, p. 48-60, 2002.

IOANNOU, G.; PAPADOYIANNIS, K. Theory of Constraints-based methodology for effective ERP implementations. International Journal Production 
Research, v. 42, n. 23, p. 4927-4954, 2004. http://dx.doi. org/10.1080/00207540410001721718

KIM, S.; MABIN, V. J.; DAVIES, J. The theory of constraints thinking processes: retrospect and prospect. International Journal of Operations \& Production Management, v. 28, n. 2, p. 155-184, 2008. http:// dx.doi.org/10.1108/01443570810846883

LACERDA, D. P.; RODRIGUES, L. H.; CASSEL, R. A. Service process analysis using process engineering and the theory of constraints thinking process. Business Process Management Journal, v. 16, p. 264-281, 2010. http://dx.doi.org/10.1108/14637151011035598

LEACH, L. P. Critical Chain Project Management Improves Project Performance. Project Management Journal, v. 30, n. 2, p. 39-51, 1999.

LEACH, L. P. Critical Chain Project Management. 2th ed. Artech House, 2005.

LECHLER, T. G.; RONEN, B.; STOHR, E. A. Critical Chain: A new project management paradigm or Old Wine in New Bottles?. Engineering Management Journal, v. 17, n. 4, p. 45-58, 2005.

MANGAN, J.; LALWANI, C.; GARDNER, B. Combining quantitative and qualitative methodologies in logistics research. International Journal of Physical Distribution \& Logistics Management, v. 34, n. 7, p. 565-578, 2004. http://dx.doi.org/10.1108/09600030410552258

MELLO, P.; ZOPPA, A.; GUIMARÃES, J. Planejamento e controle de projetos: uma abordagem prática - parte II lidando com incertezas. Mundo project management, ano 5, n. 26, p. 68-73, 2009.

MENTZER, J. T.; FLINT, D. J. Validity in Logistics Research. Journal of Business Logistics, v. 18, n. 1, p. 199-216, 1997.

MIGUEL, P. A. C. Estudo de Caso em Engenharia de Produção: estruturação e recomendações para sua condução. Produção, v. 17, n.1, p. 216-229, 2007.

MORAES, R. O.; LAURINDO, F. J. B. Um Estudo de Caso de Gestão de Portfolio de Projetos de Tecnologia da Informação. Gestão \& Produção, v. 10, n.3, p. 311-328, 2003.

NEVES, J. L. Pesquisa Qualitativa - Características, usos e possibilidades. Caderno de Pesquisas em Administração, v. 1 n. 3, p. 1-5, 1996.

NEWBOLD, R. C. Project Management in the fast lane: applying the theory of constraints. Boca Raton: St. Lucie Press, 1998. 284 p.

PROJECT MANAGEMENT INSTITUTE. The value of project management: 2008 annual report. Campus Blvd: PMI: 2009. 27 p. Disponível em: <http://www. pmi.org/About-Us/About-Us-Annual-Report.aspx>. Acesso em: 29 set. 2010.

RABECHINI JUNIOR, R.; CARVALHO, M. M.; LAURINDO, F. J. B. Fatores críticos para implementação de gerenciamento por projetos: o caso de uma organização de pesquisa. Produção, v. 12, n. 2, p. 28-41, 2002.

RAND, G. K. Critical chain: the theory of constraints applied to project management. International Journal of Project Management, v. 18, p. 173-177, 2000. Disponível em: <www.sciencedirect.com>. Acesso em: 02 nov. 2009.

RAZ, T.; BARNES, R.; DVIR, D. A Critical Look at Critical Chain Project Management. Project Management Journal, v. 34, n. 4, p. 24-32, 2003.

SILVA, E. L.; MENEZES, E. M. Metodologia da pesquisa e elaboração de dissertação. Florianópolis: Universidade Federal de Santa Catarina, 2001. 121 p. Disponível em: <http://projetos.inf.ufsc.br/arquivos/Metodologia\%20 da\%20Pesquisa\%203a\%20edicao.pdf $>$. Acesso em: 11 jul. 2009.

SILVA, E. M. Proposta de aplicação da corrente crítica no gerenciamento de projetos executivos de engenharia em uma refinaria. 2010. Trabalho de conclusão de curso (Graduação em Engenharia de Produção)-Universidade do Vale do Rio dos Sinos, São Leopoldo, 2010.

STEYN, H. An investigation into the fundamentals of critical chain project scheduling. International Journal of Project Management, n. 19, p. 363-369. 2000.

SRIVASTAVA, S. C.; TEO, T. S. H. Understanding, Assessing and Conducing Interpretative Management Research. IIMB Management Review, 2006.

SOBH, R.; PERRY, C. Research design and data analysis in realism research, European Journal of Marketing, v. 40, n. 11-12, p. 1194-1209, 2006. http://dx.doi. org/10.1108/03090560610702777

UMBLE, M.; UMBLE, E. Manage your projects for success: an application of the Theory of Constraints. Production and Inventory Management Journal, v. 41, n. 2, p. 27-31, 2000.

YANG, J. How the Critical Chain Scheduling Method is Working for Construction. Cost Engineering, v. 49, n. 4, p. 25-32, 2007.

YEO, K. T.; NING, J. H. Integrating supply chain and critical chain concepts in engineer-procure-construct (EPC) projects. International Journal of Project Management, v. 20, p. 253-262, 2002. http://dx.doi. org/10.1016/S0263-7863(01)00021-7

YIN, R. K. Estudo de caso: planejamento e métodos. Tradução de Daniel Grassi. 2. ed. Porto Alegre: Bookman, 2004. 205 p.

VARGAS, L.; MALDONADO, G. Guia para apresentação de trabalhos científicos. 3. ed. Porto Alegre: Programa de Pós-Graduação em Administração - PPGA, Universidade Federala do Rio Grande do Sul, 2001.

WALKER, E. The problems with project management. In: COX III, J. F.; SCHLEIER JUNIOR, J. G. Theory of Constraints Handbook. McGraw-Hill, 2010.

WORLEY, T. L. F. Using Constraint Management to Optimize Motion Picture Production Management. Project Management Journal, v. 36, n. 4, p. 44-52, 2005

ZULTNER, R. E. Getting Projects Out of Your System: a critical chain primer. Cutter IT Journal - The Journal of Information Technology Management, v. 16, n. 3, p. 10-18, 2003. 